$\xi=-1$

\title{
An Evaluation of Eggshell Waste/Waste Paper Mechanical Properties as Composite Paper
}

\author{
Mohammad Abdullah ${ }^{1 *}$, Soo Kum Yoke ${ }^{2}$, Danial Nuruddin Azlan Raofuddin ${ }^{1}$, Mohd Zaki Sukor ${ }^{1}$, Azmi Roslan ${ }^{1}$, \\ Siti Mariam Mohamad Ilyas ${ }^{3}$, Mohd Hanafie Yasin ${ }^{4}$ \\ ${ }^{I}$ Faculty of Chemical Engineering, Universiti Teknologi MARA, Johor Branch, Pasir Gudang Campus, Bandar Seri Alam, Johor, Ma- \\ laysia \\ ${ }^{2}$ Academy of Language Studies, Universiti Teknologi MARA, Johor Branch, Segamat Campus, Segamat, Johor, Malaysia \\ ${ }^{3}$ Academy of Language Studies, Universiti Teknologi MARA, Johor Branch, Pasir Gudang Campus, Bandar Seri Alam, Johor, Malaysia \\ ${ }^{4}$ Faculty of Civil Engineering, Universiti Teknologi MARA, Johor Branch, Pasir Gudang Campus, Bandar Seri Alam, Johor, Malaysia \\ *Corresponding author E-mail: moham3767@johor.uitm.edu.my
}

\begin{abstract}
Paper as a material, is useful. For this reason, the paper industry has contributed widely to the economy. This is also true for advancement in the technology for recycled papers. Paper fibre or paper pulp however is depleting due to extensive deforestation and loggings which in turn leads to problems such as global warming. Further, eggshell waste is a material found to be useful to produce papers. As such, this study intends to find out the possibilities of using eggshell waste and waste papers to produce papers. To carry out the research, the optimum ratio of fibre in the paper pulp was determined by the maximum strength of recycled paper produced. Eggshell waste was collected from a food court. The eggshells were then separated from their membrane, dried in the sun and grinded. It was then mixed with paper pulp according to the measured ratio. The study found that paper from a combination of eggshell fibre waste against waste paper was able to be produced and the optimum ratio was 2:8 because it had the highest tensile strength. The eggshell waste can be used as a material that enhanced the mechanical properties of recycled paper.
\end{abstract}

Keywords: paper waste; eggshell fibre waste; recycled paper; tensile strength; composite paper.

\section{Introduction}

Paper is a versatile and useful material that was invented during the second century BC. According to [1], the first person who invented proper papermaking is Tsai-Lun in AD 106. Tsai-Lun collected, improved and generalized primitive methods for paper production available at that time. Nowadays, the most commonly produced paper is made from pulp which is obtained by mechanical and chemical separation of cellulose fibres from wood.

Europe is one of the largest continents in the world to produce and consume paper. Even though consumption of paper in Europe is decreasing at present, the total amount of paper collected and recycled remains stable at just under 58 million tonnes. According to [2], the recycling rate of paper products in Europe reached almost $72 \%$ in 2012. A Multi-Criteria Decision Analysis (MCDA) had to be performed in order to ensure a proper assessment of waste paper management. In [3] asserted that environmental, legislative, economic, and social conditions need to be considered when waste management decisions are made. In the present study, fibre from eggshell waste is used as paper pulp to produce paper and to increase the strength of recycled papers.

An alternative solution for this problem is to find an alternative substance for producing paper that have an advantage to the environment, economy and social condition. Nearly $30 \%$ of eggs are consumed each year for cooking and baking purposes such as cakes, mixes, mayonnaise, noodles and fast foods. The United States of America food industry generates 150,000 tons of eggshell waste per annum [4]. There are a lot of disposal methods for eggshells waste which is $26.6 \%$ as fertilizer, $21.1 \%$ as animal feed ingredients, $26.3 \%$ discarded in municipal dumps and $15.8 \%$ used in other ways. Many landfills are unwilling to take the waste because eggshell waste attracts vermin [4]. Therefore, this study intends to proof whether eggshell waste fibre is able to produce paper and increase the strength of recycle paper.

Ancient forests are still being logged for timber in order to produce products such as paper making and this is destroying entire natural ecosystems. Paper pulp production from the paper making industry is responsible for a rapid global expansion in intensively managed tree plantations, some of which are established by clearing natural forest or other precious habitats. In fact, just one ton of recycled paper saves approximately six mature trees and 3.3 yards of rapidly diminishing landfill space [5]. The pulp and paper making industry is one of the world's largest emitters of greenhouse gases. It uses a large amount of water and energy and produces significant amounts of pollutants and landfill waste. Therefore, the composite paper from eggshell waste/paper waste was produce in this study to overcome the current problems. The objective of this study was to evaluate the mechanical properties of recycled paper that produce using recycled paper and eggshell waste.

\section{Methodology}

\subsection{Preparation of Composite Paper using Paper Waste and Eggshell Waste}

The eggshell waste was collected at UiTM Johor, Pasir Gudang Campus food court. First, it was washed under running pipe water 
to remove dirt. Next, the eggshell waste was separated from its membrane. After that, the eggshell waste was dried under the sunlight. After it was fully dried, the eggshell waste was grinded using a mechanical grinder to the point when the small particles are in a powder-like form. The eggshell fibre was collected using a Winchester bottle and stored safely at room condition.

The eggshell fibre and recycled paper was weighed based on the ratio for accuracy of measurement. The eggshell waste was blended together with the recycled paper and water by using a mechanical grinder. Finally, the mixture was placed in the paper cast (Figure 1) until it was fully dried. These steps were done repeatedly with different ratios. All these samples were then tested at the Universal Testing Machine to test their mechanical strength.

\subsection{Ratio of Paper to Eggshell Waste}

The separated eggshell waste is then mixed with recycled paper according to the ratio. Table 1 shows the ratio of the paper to fibre.

Table 1: Weight of the ratio of paper against fibre

\begin{tabular}{|c|c|c|}
\hline \multirow{2}{*}{ No. } & \multicolumn{2}{|c|}{ Waste Paper/Eggshell Waste Ratio } \\
\cline { 2 - 3 } & Weight of Paper $(\mathrm{g})$ & Weight of Eggshell $(\mathrm{g})$ \\
\hline 1 & 8 & 2 \\
\hline 2 & 7 & 3 \\
\hline 3 & 6 & 4 \\
\hline 4 & 5 & 5 \\
\hline 5 & 4 & 6 \\
\hline
\end{tabular}

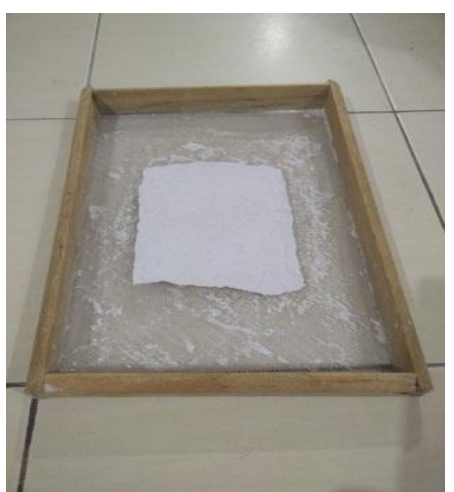

Fig. 1: The paper cast that used to make paper.

\section{Results and Discussion}

\section{Evaluation of Tensile Strength for Composite paper}

The tensile strength test by means of using the Universal Testing Machine (UTM) was conducted at the mechanical engineering laboratory at UiTM Pulau Pinang. Tensile strength is the maximum stress of a material that can hold out, while being stretched or pulled before the material fails or breaks. Tensile strength is measured as force per unit area or Newtons per square meter $\left(\mathrm{N} / \mathrm{m}^{2}\right)$ or pascal $(\mathrm{Pa})$, which is the International System of Units (SI) for stress.

From the result of the Universal Testing Machine, the graph of stress and strain was obtained. Table 2 shows the value of maximum force and maximum stress for each ratio. From the details of the result, the strength of the samples was determined by the value of maximum force and maximum stress. As in Table 2, it shows the maximum force and maximum stress applied to the sample. Figure 2 shows the force applied to the sample. It shows that the optimum ratio of paper against fibre in terms of weight in grams $(\mathrm{g})$ is $8: 2$.
Table 2: Maximum force and maximum stress applied to the sample

\begin{tabular}{|c|c|c|}
\hline $\begin{array}{c}\text { Ratio of Paper } \\
\text { to Fibre }\end{array}$ & $\begin{array}{c}\text { Maximum } \\
\text { Force }(\mathrm{kN})\end{array}$ & $\begin{array}{c}\text { Maximum } \\
\text { Stress }\left(\mathrm{N} / \mathrm{mm}^{2}\right)\end{array}$ \\
\hline $10: 0$ & 0.01875 & 1.04167 \\
\hline $8: 2$ & 0.03438 & 0.95486 \\
\hline $7: 3$ & 0.01875 & 0.52083 \\
\hline $6: 4$ & 0.02187 & 0.60764 \\
\hline $5: 5$ & 0.01719 & 0.47743 \\
\hline $4: 6$ & 0.01875 & 0.52083 \\
\hline
\end{tabular}

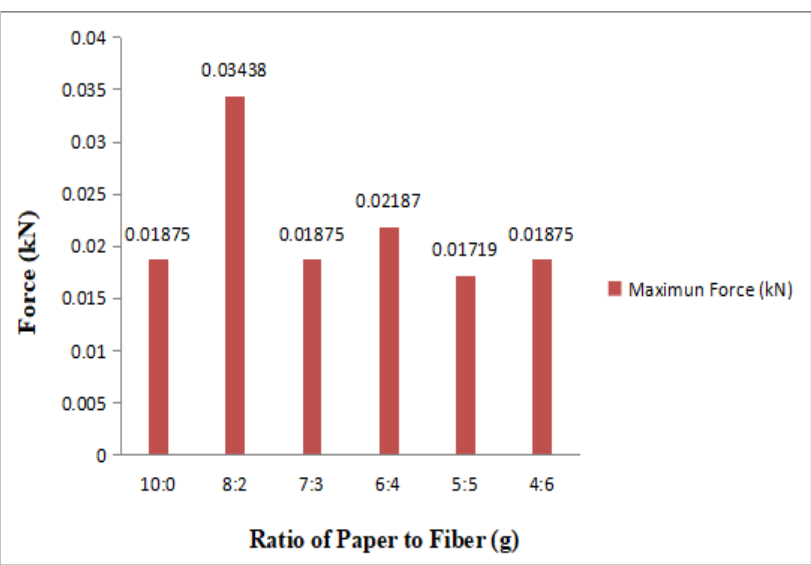

Fig. 2: Maximum force applied to the composite paper for each ratio.

Figure 2 shows that the optimum ratio of paper against eggshell waste fibre is $8: 2$. This means that it has the maximum force applied which is $0.03438 \mathrm{kN}$. One of the reason is it contains more paper than fibre and therefore that makes it thicker and stronger than the other samples. The fibre from eggshell waste is in the powder state, which is really fine. Thus, more fibre added would make the paper thinner and weaker. Generally, the force that was applied to the sample is tension force. Tension is the pulling or stretching force exerted by each end of an object [6]. The Universal Testing Machine detected the maximum tension force when the sample broke or tore. Therefore, the sample of ratio of paper against fibre 8:2 is considered as good quality in terms of strength as it needed high tension force to break or tear. The other ratio of paper against pulp easily broke because it only needs very low tension force applied to break or tear. Figure 3 shows the stress applied to the sample. It shows that the optimum ratio of paper against fibre in terms of weight in grams $(\mathrm{g})$ is 8:2.

Figure 3 shows that the optimum ratio of paper against fiber is 8:2 as it has maximum stress applied to it which is $0.95486 \mathrm{~N} / \mathrm{mm}^{2}$. The stress applied to the material is the force per unit area. Therefore, the maximum stress can be determined by how long a material can withstand before it breaks [7]. This situation is called the breaking stress or ultimate tensile stress. Tensile can be defined as the material under tension. The tension forces acting on it are trying to stretch the material until it breaks or tears. From the figure above, the paper with a ratio of paper against paper 8:2 has a good mechanical strength because it has the maximum stress applied compared to the other ratio of paper against fibre.

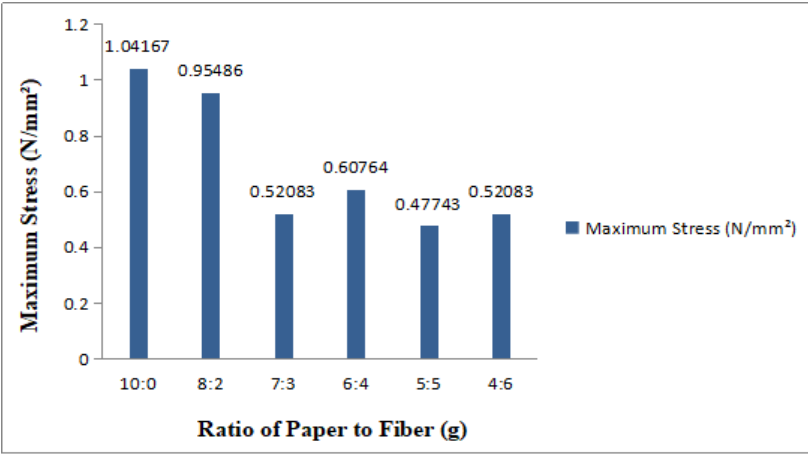

Fig. 3: Maximum force applied to the composite paper for each ratio. 
From both of the results gathered, the conclusion that can be made is the optimum ratio of the paper against fibre is $8: 2$. Compared to the other ratio, the $8: 2$ ratio of paper against fibre has a higher value of maximum force and maximum stress. Therefore, it is suitable to use for multipurpose material such as food packaging because it is difficult to break or tear. Previous studies were found to test the mechanical strength of paper by using durian shells as fibre. It stated that the best ratio of paper against durian shells fibre as 7:3. This is because the durian shell fibre are in a coarse or crumb state. For eggshell waste fibre, it is in a powder state, which is why the paper produced is thinner when more eggshell waste fibre is used.

\section{Conclusion}

The main objective of this research is to produce a recycled paper by using eggshell waste as an additional material and to determine the optimum ratio of fibre against paper pulp to get maximum tensile strength. This study proves clearly that the process of producing paper by using eggshell wastes an additional material is simple and very efficient at laboratory scale.

In this research, the first main objective is achieved when a paper is produced from a combination of waste paper and fibre of eggshell waste. By using a simple method of producing paper, the fibre was added to waste paper according to the suitable and relevant ratio which is paper against fibre, 8:2, 7:3, 6:4, 5:5, 4:6. The ratio was determined by weight in grams $(\mathrm{g})$ because it is more accurate and efficient to do so.

The second objective is achieved when the optimum ratio of paper against fibre were determined. The result obtained by Universal Testing Machine indicates the optimum ratio of paper against pulp is $8: 2$, because it has the maximum tensile strength. This result proved that the paper only needs small amounts of eggshell waste fibre to produce a paper with the maximum tensile strength. This is because the fibre of the eggshell waste is so fine and it is in powder state. Compared to the previous research, the researcher used durian shell as fibre and obtained the ratio of paper against pulp 7:3 which is slightly different from this research result. This is because the fibre from durian shell is longer and coarser from eggshell waste fibre which is fine and in powder state.

In conclusion, this paper can be useful to a lot of industries because of the maximum tensile strength. One of the industry is food packaging using polystyrene because it is non-biodegradable substance which cannot be decomposed and also contains harmful materials which effect the environment. Therefore, this paper which is good in mechanical strength has a very high potential to replace the polystyrene because paper is a biodegradable substance, easy to decompose and very safe to use widely.

\section{Acknowledgement}

We would like to express our gratitude to Faculty of Chemical Engineering Universiti Teknologi MARA Johor Branch and Faculty of Mechanical Engineering Universiti Teknologi MARA Pulau Pinang Branch for supported by giving the opportunity to use the laboratory facilities.

\section{References}

[1] Rückert, P., Hode_cek, S., Wenger, E., The History of Paper and Watermarks from the Middle Ages to the Modern Period. Landesarchiv Baden-Württemberg, Hauptstaatsarchiv Stuttgart. Austrian Academy of Sciences (2009).

[2] Paper Recycling Monitoring Report (2012) within European Declaration on Paper Recycling. European Recovered Paper Council (ERPC).

[3] Hanan, D., Burnley, S., Cooke, D., (2012), A Multi-criteria Decision Analysis Assessment of Waste Paper Management Options. Waste Management, 33(3):566-573.
[4] Sonenklar, C. (1999). Famous for eggwaste, Penn state news. Accessonline-

http://news.psu.edu/story/140891/1999/09/01/research/famous-eggwaste.

[5] Kang, T. and Paulapuro, H., (2006), Recycle Potential of Externally Fibrillated Chemical Pulp. Progress in Paper Recycling, 2, 11-17.

[6] Retulainen, E. (1992), Strength properties of mechanical and chemical pulp blends. Paperi ja Puu - Paper and Timber 74, 419. 426.

[7] Mohlin, U. B., Dahlbom, J., Hornatowska, (1996), Fibre deformation and sheet strength. Tappi Journal, 79, 105-111. 